\title{
Kinetic study on thermal decomposition of toluene in a micro fluidized bed reactor
}

\author{
Chao Gai ${ }^{a}$, Yuping Dong ${ }^{\mathrm{b}, *}$, Pengfei Fan ${ }^{\mathrm{b}}$, Zhaoling Zhang ${ }^{\mathrm{c}}$, Jingcui Liang ${ }^{\mathrm{c}}$, Pengju Xu ${ }^{\mathrm{c}}$ \\ ${ }^{a}$ Research Center for Eco-Environmental Sciences, Chinese Academy of Sciences, 18 Shuangqing Road, Beijing 100085, PR China \\ ${ }^{\mathrm{b}}$ School of Mechanical Engineering, Shandong University, Jinan 250061, PR China \\ ' Shandong Baichuan Tongchuang Energy Company Ltd., Jinan 250101, PR China
}

\section{A R T I C L E I N F O}

\section{Article history:}

Received 23 June 2015

Accepted 14 September 2015

Available online 23 October 2015

\section{Keywords:}

Biomass

Tar

Toluene

Pyrolysis

Activation energy

Micro fluidized bed reactor

\begin{abstract}
A B S T R A C T
This study concerned the pyrolysis behavior of toluene as the tar model compound. Pyrolysis experiments were carried out in a micro fluidized bed reactor (MFBR) under an isothermal condition. Pyrolysis kinetics for the gas components, including hydrogen, methane, ethylene and propane were calculated based on the model-free and model-fitting methods. Results showed that methane and ethylene were the major gas components at lower temperatures $\left(650-800^{\circ} \mathrm{C}\right)$ while propane and ethylene were the main composition of pyrolysis gas mixture at higher temperatures $\left(800-850^{\circ} \mathrm{C}\right)$. For the range of conversion fraction (20-80\%), the apparent activation energy of propane $(16.34 \mathrm{~kJ} / \mathrm{mol})$ was lower than that of ethylene $(17.59 \mathrm{~kJ} / \mathrm{mol})$, then accompanied with methane $(23.27 \mathrm{~kJ} / \mathrm{mol})$ and hydrogen $(69.55 \mathrm{~kJ} / \mathrm{mol})$. The most probable reaction mechanism for the generation of hydrogen was three-dimensional diffusion while the evolution profiles of methane could be described by the mechanism of nucleation and growth. Chemical reaction was the most probable reaction mechanism for ethylene and propane. Results from the present study indicated that MFBR can enable a quicker reaction within the reactor than other traditional approaches. The generation of propane is easier to proceed compared to other hydrocarbons with smaller carbon numbers during pyrolysis of toluene. A comparison of kinetic models and experimental results suggested that the developed models closely predicted the thermal cracking behavior of toluene.
\end{abstract}

(c) 2015 Elsevier Ltd. All rights reserved.

\section{Introduction}

Biomass has gained increasing attention due to the depletion of fossil fuels and environmental issues. Gasification is a typical technique to convert biomass to syngas for combustion/power generation [1,2]. However, tar is an inevitable byproduct during the gasification process [3-6]. Tar in the raw gases will coagulate into viscous liquid when the temperature is lower than its dew point. It will render a blockage of pipeline, filters, turbines and engines, which seriously affect the steady operation of the reactor system [7]. Consequently, tar reduction has become one of the most urgent problems for biomass utilization. Thermal cracking can convert tar into lighter gases at high temperatures without waste of extra energy retained in the tar [8,9]. It is an effective method to improve the quality of gaseous products during the conversion process.

The approach of modeling is expected to help design and scaleup of gasifier, optimization of operating conditions and prediction of reaction behavior. Besides, modeling can save more money and

\footnotetext{
* Corresponding author. Tel.: +86 531 88392199; fax: +86 53188873588 .

E-mail address: dongyp@sdu.edu.cn (Y. Dong).
}

time compared to experiments, especially at a large scale $[10,11]$. Despite there is a certain amount of errors in the simulation results due to the simplified assumption, mathematical models have been observed to be effective in predicting the thermal cracking process. Many researchers have developed various mathematical models for the biomass gasification process, such as equilibrium, kinetic, and CFD models. Equilibrium model can provide the designer with a prediction of maximum yield of a desired product during the gasification process. However, the equilibrium conditions are not the real conditions inside the reactor, and thus the results are less reliable. Kinetic model involves parameters like reaction rate can provide a more accurate simulation for the reaction behavior, and the kinetic data is necessary for CFD modeling. Thermogravimetric analysis (TGA) is an universal approach to carry out kinetic modeling [12-14]. A certain amount of the sample has degraded before the temperature within the reactor reaching the desired level. Besides, it can't be operated under high gas velocity, which will make reactions restrained by diffusion. Therefore, the overall kinetics based on TGA can hardly reflect the intrinsic characteristics of thermal cracking of tar. To address these disadvantages, micro fluidized bed reactor (MFBR) $[15,16]$ has 
been developed to investigate the kinetics of thermo-chemical conversion of biomass/model compounds. Micro fluidized bed is designed as the main body of the MFBR system to intensify heat and mass transfer within the reactor. Additionally, the mass loss in the initial stage of reaction can be avoided due to instantaneous feeding of reactants at desired reaction temperatures. It has been verified that this experimental system is effective in cases of thermo-chemical conversion of biomass. Besides, the kinetic parameters determined based on MFBR are less sensitive to the experimental noise and meet the intrinsic kinetic parameters better $[17,18]$.

Tar is a complex organic compound, which is viewed as aggregate of oxygenates, phenolic compounds and olefins, aromatic and poly aromatic hydrocarbons (PAH). To overcome the complexity of the tar, model compounds have been used as reference in experimental or kinetic works for the thermal cracking of different tar components $[19,20]$. Although the composition and content of tar vary with gasification conditions, types of reactor or feedstock, the most commonly tar model compounds in previous literature are light tar compounds like benzene, toluene, phenol and cresols as well as heavy tar compounds such as naphthalene and anthracene. According to Sun et al. [21], during biomass gasification, part of heavy tar was thermal cracked to light tar at relatively low temperatures $\left(500-600^{\circ} \mathrm{C}\right)$. However, at higher temperatures $\left(700-800^{\circ} \mathrm{C}\right.$ ), the tar with heavy molecular weight was very resistant to cracking although the thermal cracking was the principal reaction of tar reduction. Gil et al. [22] investigated the impact of temperature on tar composition from wood gasification. It was observed that toluene, phenol and cresols were predominant at $700{ }^{\circ} \mathrm{C}$, while naphthalene was the major components at $900^{\circ} \mathrm{C}$. Brage et al. [23] also observed a 50\% decrease in toluene content when the temperature was raised from 700 to $900{ }^{\circ} \mathrm{C}$. Conversely, the content of naphthalene increased gradually. Coll et al. [24] studied the pyrolysis behavior of tar model compounds. It was concluded that the order of these tar's reactivity was: benzene $>$ toluene $>$ anthracene $>$ pyrene $>$ naphthalene. Anis et al. [25] also concluded that toluene was much easier to be degraded than naphthalene. It suggests that the approach of thermal cracking in a certain temperature is more feasible for reduction of light tar instead of heavy tar. Therefore, the present study was more concerned about light tar, and toluene was chosen as the tar model compound due to its high content in the tar.

To date, many studies have been concerned on pyrolysis behavior and kinetics of toluene based on different heating reactors. Taralas et al. [26] studied thermal destruction of toluene in a nonisothermal tubular flow reactor. It was concluded that a first-order reaction rate could express the effects of temperature and residences on the toluene conversion process. Mani et al. [27] investigated the catalytic decomposition of toluene in a continuous flow packed bed reactor, and the kinetics of toluene removal was also found to follow first order reaction. Anis and Zainal [28] evaluated kinetic parameters for toluene conversion under microwave thermocatalytic treatment. It was concluded that the overall reaction rate was six times higher compared to conventional heating. It suggests that different heating strategy has a great effect on the decomposition of toluene, kinetic analysis should also be carried out for interpreting the experimental observations in MFBR. The current paper focused on the thermal decomposition behavior of toluene in MFBR. Then the kinetic parameters and most probable reaction mechanisms for the major gaseous products during toluene decomposition reactions were determined. The kinetic model was validated by comparing the prediction results to experimental results. These data may contribute to a better understanding of thermal cracking of tar.

\section{Experimental}

\subsection{Reactor system}

The scheme of MFBR is illustrated in Fig. 1. It mainly consists of a stainless steel syringe pump, a micro fluidized bed and a process mass spectrometer (Dycor ProLine, Ametek, USA). The micro fluidized bed mainly consists of heating furnace, quartz reactor and flow/pressure sensors. The quartz reactor is capable of bearing high temperatures around $1200^{\circ} \mathrm{C}$. The dimension of the quartz reactor is described as follows: the diameter is $290 \mathrm{~mm}$; the height is $373 \mathrm{~mm}$; the reaction zone's inner diameter is $20 \mathrm{~mm}$ and the height is $42 \mathrm{~mm}$. The inner diameter of injection pipe is $3 \mathrm{~mm}$. The flow rates of fluidizing gas and pulse gas are adjusted by the mass flow meter to maintain a steady-state of fluidization within the reactor. The process mass spectrometer can measure the relative content of gaseous products during the thermal decomposition of tar model compound online. The temperatures of the furnace and reactor, the pressures of the reactor and the actions of the sample injection system are all controlled by the computer.

\subsection{Test procedure}

For each test, the fluidization medium was quartz sand with particle sizes ranging from 65 to 80 meshes. The whole system was purged with argon (99.99\% purity) as carrier gas and fluidizing gas. At the beginning of the test, $3.0 \mathrm{~g}$ of quartz sand as the fluidizing medium was loaded into the micro fluidized bed. The reactor system was sealed and then the fluidizing gas was fed to the reactor to fluidize the quartz sand in the reactor. When the reactor was heated to the preset temperatures, $10 \mathrm{ml}$ of the toluene was fed into the reactor by the syringe pump. The produced gas was monitored online by the process mass spectrometer. According to Jess [29], the main products of pyrolysis of polycyclic aromatic hydrocarbons are hydrocarbons with smaller carbon numbers, and the intermediates are formed only to a limited extent. Therefore, this study concerned about the evolution properties of light gases in terms of hydrogen $\left(\mathrm{H}_{2}\right)$, methane $\left(\mathrm{CH}_{4}\right)$, ethylene $\left(\mathrm{C}_{2} \mathrm{H}_{4}\right)$ and propane $\left(\mathrm{C}_{3} \mathrm{H}_{8}\right)$. The corresponding gas yield (in mass against fuel) was determined by sampling the produced gas in the entire reaction time and in turn analyzed via a Micro-GC 3000. The total gas yield was the sum of yields of four produced gases mentioned above.

According to the literature $[29,30]$, the optimum temperatures for thermal cracking of aromatic hydrocarbons ranged from $500{ }^{\circ} \mathrm{C}$ to $1200^{\circ} \mathrm{C}$. Dufour et al. [31] investigated the evolution of aromatic tar composition as a function of reaction temperature during pyrolysis of woody biomass in a quartz tubular reactor. It was reported that toluene was almost completely converted into PAHs between $800^{\circ} \mathrm{C}$ and $900{ }^{\circ} \mathrm{C}$, which is also consistent with Evans and Milne [32]. Świerczyński et al. [33] concluded that the most favorable conditions for investigating the toluene conversion were above $650{ }^{\circ} \mathrm{C}$. Consequently, the preset temperatures in this study for pyrolysis of toluene were selected between $650{ }^{\circ} \mathrm{C}$ and $850^{\circ} \mathrm{C}$ with intervals of $50^{\circ} \mathrm{C}$. Previous study [19] measured the temperature in the main reaction zone of MFBR during the pyrolysis process. It was observed that the temperature remained steady for a certain temperature, enabling an isothermal condition in MFBR.

To ensure complete fluidization of quartz sand, several preliminary tests were carried out to determine the optimum gas flow rate. We studied the effect of gas flow rate $(100-900 \mathrm{ml} / \mathrm{min})$ on the total gas yield at different temperatures $\left(650-850{ }^{\circ} \mathrm{C}\right)$. It was observed that at any temperatures $\left(650-850^{\circ} \mathrm{C}\right)$, the total gas yield 


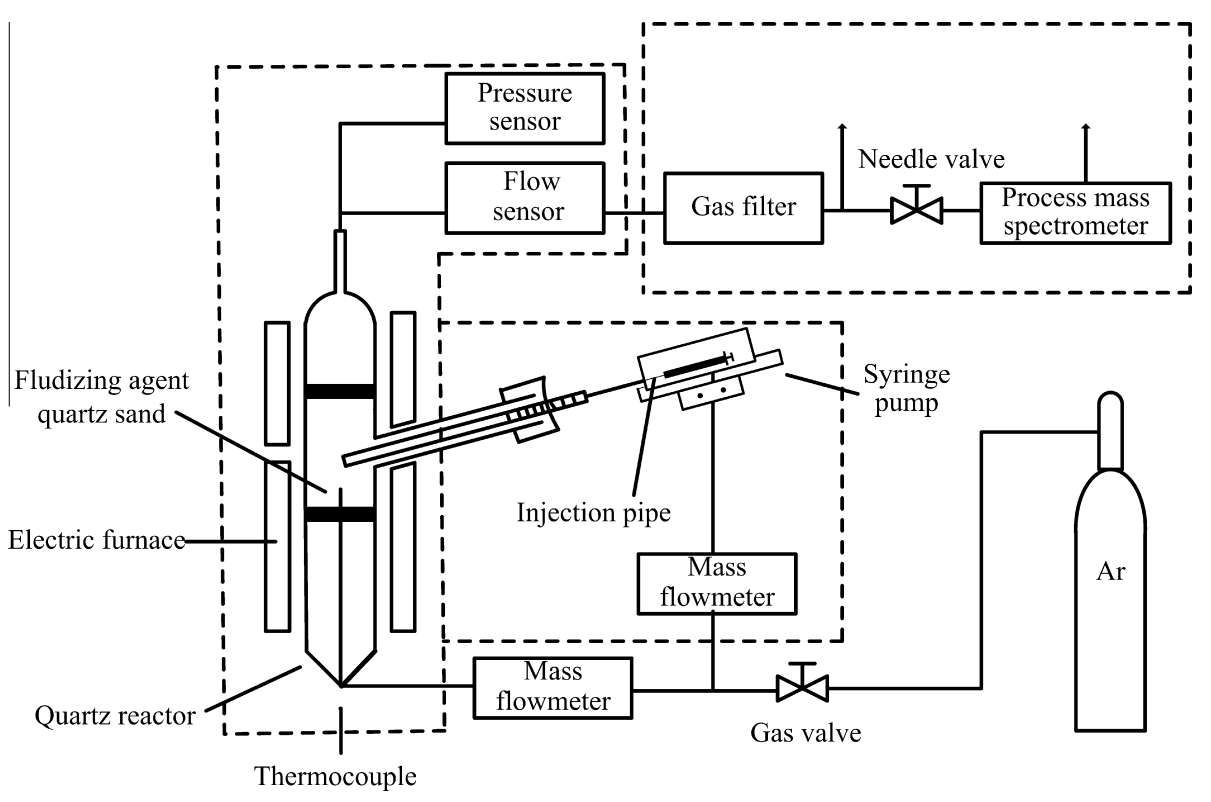

Fig. 1. Scheme diagram of the micro fluidized bed reactor system.

gradually increased with the increase of gas flow rate when the gas flow rate was lower than $500 \mathrm{ml} / \mathrm{min}$. The total gas yield varied little with the fluidizing gas flow rate when the rate was higher than $500 \mathrm{ml} / \mathrm{min}$. Therefore, it was inferred that the fluidization medium of quartz sand was not fully fluidized at $100-500 \mathrm{ml} / \mathrm{min}$ and thus resulted in a slow reaction rate, which decreased the gas yield. The flow rate was all kept at $500 \mathrm{ml} / \mathrm{min}$ in this study.

\section{Results and discussion}

\subsection{Gas yields}

Table 1 illustrated the gas yields at different reaction temperatures $\left(650-850^{\circ} \mathrm{C}\right)$ during pyrolysis of toluene in MFBR. The total gas yield was observed to be gradually increased from $57.72 \mathrm{wt} . \%$ at $650{ }^{\circ} \mathrm{C}$ to $87.96 \mathrm{wt} . \%$ at $850^{\circ} \mathrm{C}$. It indicates that during the gasification process, toluene as light tar can be almost completely cracked to lighter gases at temperatures higher than $800^{\circ} \mathrm{C}$. Besides, $\mathrm{C}_{2} \mathrm{H}_{4}$ and $\mathrm{C}_{3} \mathrm{H}_{8}$ made up a large percentage of total gas yield at lower temperatures of $650-800{ }^{\circ} \mathrm{C}$, while lighter gases (i. e. $\mathrm{CH}_{4}$ and $\mathrm{C}_{2} \mathrm{H}_{4}$ ) were the major part of pyrolysis gas yield at higher temperatures of $800-850{ }^{\circ} \mathrm{C}$. Jess [29] investigated the pyrolysis of aromatic hydrocarbons as tar model compounds. It was observed that the major cracking products from toluene at temperatures higher than $950^{\circ} \mathrm{C}$ were $\mathrm{CH}_{4}$ and $\mathrm{C}_{2} \mathrm{H}_{4}$, which agrees well with the results in the present study.

The variations of gaseous products were not a monotonic trend. To be specific, the yields of $\mathrm{H}_{2}$ increased continuously from 1.73 wt.\% at $650{ }^{\circ} \mathrm{C}$ to $12.31 \mathrm{wt} . \%$ at $850{ }^{\circ} \mathrm{C}$. This trend is consistent with the variation of $\mathrm{H}_{2}$ yield during the pyrolysis of toluene as tar

Table 1

Conversion of toluene at different temperatures.

\begin{tabular}{lccccc}
\hline \multirow{2}{*}{ Temperature $\left({ }^{\circ} \mathrm{C}\right)$} & \multicolumn{3}{c}{ Gas yield (wt.\%) } & \multirow{2}{*}{$\begin{array}{l}\text { Total gas } \\
\text { yield (wt.\%) }\end{array}$} \\
\cline { 2 - 5 } & \multicolumn{1}{c}{$\mathrm{H}_{2}$} & $\mathrm{CH}_{4}$ & $\mathrm{C}_{2} \mathrm{H}_{4}$ & $\mathrm{C}_{3} \mathrm{H}_{8}$ & \\
\hline 650 & 1.73 & 5.77 & 32.49 & 17.73 & 57.72 \\
700 & 3.60 & 5.44 & 39.77 & 14.65 & 63.47 \\
750 & 5.94 & 5.50 & 50.69 & 12.09 & 74.22 \\
800 & 7.37 & 11.71 & 52.15 & 10.64 & 81.87 \\
850 & 12.31 & 23.75 & 42.20 & 9.69 & 87.96 \\
\hline
\end{tabular}

model compound [28] or real biomass like straw [30]. The yield of $\mathrm{CH}_{4}$ didn't vary greatly when temperature was increased from $650{ }^{\circ} \mathrm{C}$ to $750{ }^{\circ} \mathrm{C}$, and then increased significantly from $5.5 \mathrm{wt} . \%$ at $750{ }^{\circ} \mathrm{C}$ to $23.75 \mathrm{wt} . \%$ at $850^{\circ} \mathrm{C}$. The $\mathrm{C}_{2} \mathrm{H}_{4}$ yield increased from 32.49 wt.\% at $650{ }^{\circ} \mathrm{C}$ to 52.15 wt.\% at $800{ }^{\circ} \mathrm{C}$, and then decreased to 42.20 wt.\% at $850{ }^{\circ} \mathrm{C}$. The yield of $\mathrm{C}_{3} \mathrm{H}_{8}$ gradually decreased from 17.73 wt.\% at $650{ }^{\circ} \mathrm{C}$ to 9.69 wt.\% at $850{ }^{\circ} \mathrm{C}$. The variations of gaseous products suggest that the main reaction pathway for gaseous products during pyrolysis of toluene is cracking reaction leading to hydrocarbons with smaller carbon numbers. The reaction of $\mathrm{CH}_{4}(\mathrm{~g}) \rightarrow \mathrm{C}(\mathrm{s})+2 \mathrm{H}_{2}(\mathrm{~g})$ is favored with an increase in temperature from $650{ }^{\circ} \mathrm{C}$ to $850^{\circ} \mathrm{C}$. The reaction of $\mathrm{C}_{3} \mathrm{H}_{8}(\mathrm{~g}) \rightarrow \mathrm{C}_{2} \mathrm{H}_{4}(\mathrm{~g})+\mathrm{CH}_{4}(\mathrm{~g})$ is promoted at lower temperatures $\left(650-800^{\circ} \mathrm{C}\right)$ while the reaction of $\mathrm{C}_{2} \mathrm{H}_{4}(\mathrm{~g}) \rightarrow \mathrm{C}(\mathrm{s})+\mathrm{CH}_{4}(\mathrm{~g})$ is favored at higher temperatures $\left(800-850^{\circ} \mathrm{C}\right)$.

\subsection{Releasing properties of major gas components}

During the thermal decomposition of toluene in MFBR, the conversion fraction of each gas composition can be determined as:

$x=\frac{\int_{t_{0}}^{t} C_{i} \times C d t}{\int_{t_{0}}^{t_{e}} C_{i} \times C d t} \times 100 \%$

where $C_{i}$ is the rate of the volume fraction for the gas composition $i, C$ is the rate of volume for all gas components, $t_{0}$ is the start time of pyrolysis reaction, $t_{e}$ is the end time of pyrolysis reaction. It should be noted that the conversion of $100 \%$ corresponds to the largest gas yield at the end of the reaction.

Fig. 2 illustrated the evolution profiles of major gas products $\left(\mathrm{H}_{2}, \mathrm{CH}_{4}, \mathrm{C}_{2} \mathrm{H}_{4}\right.$ and $\left.\mathrm{C}_{3} \mathrm{H}_{8}\right)$ produced by pyrolysis of toluene in MFBR. It can be seen in Fig. 2 that at any reaction temperature, the conversion fractions for four gas components all increased quickly and the major conversion process (20-80\%) for all gas compositions usually took three seconds. The time taken to the attainment of reaction equilibrium for gaseous products in MFBR is much shorter than that of pyrolysis tube (about $10 \mathrm{~min}$ ) [34] and pressurized fluidized-bed (around $80 \mathrm{~min}$ ) [23]. The quick reaction process is because the sample was sent into the reactor at the required temperature instead of the room temperature. It suggests that the 

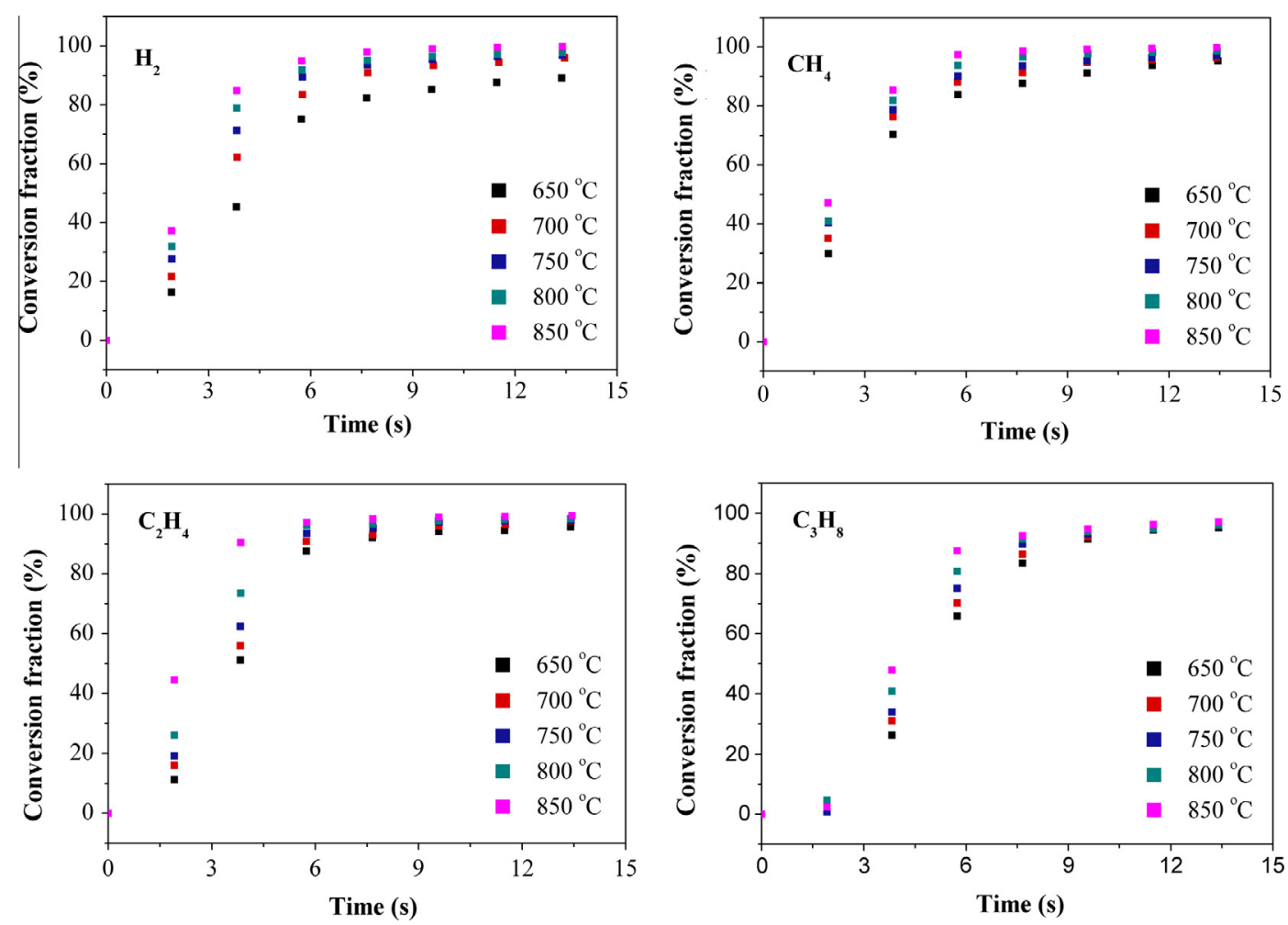

Fig. 2. Gas evolution profiles during pyrolysis of toluene in MFBR.

reaction in MFBR is mainly controlled by reaction kinetics rather than diffusion.

Fig. 2 also demonstrated that the pyrolysis temperature greatly affected the evolution profiles of all gas components during toluene pyrolysis. For each gas component, the residence time spent on reaching the same conversion fraction was gradually shortened with the increase of temperature from $650{ }^{\circ} \mathrm{C}$ to $850^{\circ} \mathrm{C}$. This is probably because toluene decomposition is an endothermic reaction [35]. A higher temperature increases the reaction rate of the thermal cracking of toluene to generate gaseous products.

\subsection{Pyrolysis kinetics of toluene in MFBR}

\subsubsection{Variation of apparent activation energies}

Based on the measurements of the conversion fractions of gas components as a function of reaction time at five reaction temperatures ranging from $650^{\circ} \mathrm{C}$ to $850^{\circ} \mathrm{C}$, the kinetic parameters of toluene pyrolysis in MFBR were determined. Pyrolysis of toluene in MFBR is a typical heterogeneous reaction under isothermal condition, which can be described as [36]:

$\frac{d x}{d t}=k(T) f(x)$

where $T$ is the reaction temperature, $t$ is the reaction time, $x$ is the conversion fraction, which is calculated according to Eq.(1), $f(x)$ is the differential function of conversion, $k(T)$ is the reaction rate constant, which can be described by the Arrhenius equation:

$k(T)=A \exp \left(-E_{a} / R T\right)$

where $E_{a}$ is the apparent activation energy, $\mathrm{kJ} \mathrm{mol}^{-1}, A$ is the preexponential factor, $\mathrm{s}^{-1}, R$ is the gas constant, $8.314 \mathrm{~J}(\mathrm{~mol} \mathrm{~K})^{-1}$.

Friedman-Reich-Levi method [37] is one of the most common model-free methods for calculating the kinetic parameters, which is used to determine the apparent activation energies of toluene pyrolysis in the present study.

Taking the logarithm of both sides of Eq. (2):

$\ln \frac{d x}{d t}=\ln k(T)+\ln f(x)$

Taking the logarithm of both sides of Eq. (3):

$\ln k(T)=\ln A-\frac{E_{a}}{R T}$

Substituting Eq. (5) into Eq. (4):

$\ln \frac{d x}{d t}=-\frac{E_{a}}{R T}+\ln A+\ln f(x)$

For a given temperature, the points of $\ln (d x / d t)$ versus $1 / T$ at different conversion fractions can be fitted to a straight line. The slope of the line corresponds to $-E_{a} / R T$, which can determine the apparent activation energy. This model-free method doesn't need to assume a reaction model before determining the apparent activation energy. It can ignore the inaccuracy brought by the kinetic compensation effect [38]. Table 2 presented the variations of apparent activation energy at different conversion fractions for major gas components during the toluene pyrolysis.

Table 2 illustrated that the average value of apparent activation energy $(16.34 \mathrm{~kJ} / \mathrm{mol})$ for propane was lower than that of ethylene $(17.59 \mathrm{~kJ} / \mathrm{mol})$, then accompanied with methane $(23.27 \mathrm{~kJ} / \mathrm{mol})$ and hydrogen $(69.55 \mathrm{~kJ} / \mathrm{mol})$. The reaction rate of a reaction with lower apparent activation energy is faster due to the lesser energy required to break down the chemical bonds between atoms [39]. According to Anis and Zainal [28], the formation of hydrocarbons is more favorable than that of hydrogen during conversion of toluene, which is consistent with the results in the present study. In addition, it can be concluded in the present study that during toluene conversion, the generation of propane is easier to proceed compared to other hydrocarbons with smaller carbon numbers. 
Table 2

Apparent activation energies for individual gas components.

\begin{tabular}{|c|c|c|c|c|c|c|c|c|c|}
\hline Gas & Conversion fraction (\%) & $R^{2}$ & $S D$ & $E_{a}(\mathrm{~kJ} / \mathrm{mol})$ & Gas & Conversion fraction (\%) & $R^{2}$ & $S D$ & $E_{a}(\mathrm{~kJ} / \mathrm{mol})$ \\
\hline \multirow[t]{8}{*}{$\mathrm{H}_{2}$} & 20 & 0.909 & 0.049 & 49.07 & \multirow[t]{8}{*}{$\mathrm{CH}_{4}$} & 20 & 0.914 & 0.035 & 35.89 \\
\hline & 30 & 0.932 & 0.043 & 61.67 & & 30 & 0.952 & 0.014 & 28.44 \\
\hline & 40 & 0.997 & 0.035 & 67.90 & & 40 & 0.932 & 0.010 & 19.69 \\
\hline & 50 & 0.999 & 0.016 & 77.85 & & 50 & 0.973 & 0.004 & 19.55 \\
\hline & 60 & 0.989 & 0.017 & 80.25 & & 60 & 0.920 & 0.024 & 15.22 \\
\hline & 70 & 0.962 & 0.028 & 80.85 & & 70 & 0.940 & 0.038 & 17.08 \\
\hline & 80 & 0.945 & 0.044 & 69.24 & & 80 & 0.906 & 0.045 & 27.03 \\
\hline & Average & & & 69.55 & & Average & & & 23.27 \\
\hline \multirow[t]{8}{*}{$\mathrm{C}_{2} \mathrm{H}_{4}$} & 20 & 0.926 & 0.039 & 25.24 & \multirow[t]{8}{*}{$\mathrm{C}_{3} \mathrm{H}_{8}$} & 20 & 0.931 & 0.039 & 10.64 \\
\hline & 30 & 0.939 & 0.035 & 21.48 & & 30 & 0.932 & 0.036 & 10.72 \\
\hline & 40 & 0.964 & 0.027 & 19.24 & & 40 & 0.963 & 0.025 & 13.35 \\
\hline & 50 & 0.989 & 0.015 & 10.04 & & 50 & 0.980 & 0.036 & 14.55 \\
\hline & 60 & 0.981 & 0.024 & 13.67 & & 60 & 0.927 & 0.017 & 16.12 \\
\hline & 70 & 0.970 & 0.029 & 15.15 & & 70 & 0.983 & 0.033 & 20.68 \\
\hline & 80 & 0.959 & 0.046 & 18.29 & & 80 & 0.970 & 0.043 & 28.31 \\
\hline & Average & & & 17.59 & & Average & & & 16.34 \\
\hline
\end{tabular}

Swierczynski et al. [33] investigated the steam reforming of toluene in a fixed bed reactor using a Ni/olive catalyst. It was reported that the apparent activation energy for thermal decomposition of toluene was $196 \mathrm{~kJ} / \mathrm{mol}$. Mani et al. [27] investigated the catalytic decomposition of toluene in a continuous flow packed bed reactor and the activation energy was determined to be $91 \mathrm{~kJ} /-$ mol. According to Taralas et al. [26], the apparent activation energy for the thermal cracking of toluene in a tubular flow reactor with gas mixture of steam and hydrogen was $247 \mathrm{~kJ} / \mathrm{mol}$ while the corresponding value was $356 \mathrm{~kJ} / \mathrm{mol}$ with the gas mixture of steam and oxygen. Anis and Zainal [28] calculated the kinetic parameters for toluene conversion under microwave thermocatalytic treatment, and found that the apparent activation energies for thermal decomposition of toluene were in the range of 3-27 kJ/mol. In this study, the apparent activation energy of pyrolysis of toluene in MFBR was in the range of $16.34-69.55 \mathrm{~kJ} / \mathrm{mol}$, which is lower compared to those conventional thermal treatments reported in the literature and close to the results reported by microwave thermocatalytic treatment. One of the main reasons of the discrepancy of activation energy for different thermal treatment of tar model compound is due to the different heating strategy.

Additionally, Table 2 illustrated that the apparent activation energy of different gas components all varied greatly as a function of conversion fraction instead of keeping constant. Specifically, the apparent activation energy for hydrogen increased first from $49.07 \mathrm{~kJ} / \mathrm{mol}$ at $20 \%$ to $80.85 \mathrm{~kJ} / \mathrm{mol}$ at $70 \%$, and then decreased to $69.24 \mathrm{~kJ} / \mathrm{mol}$ at $80 \%$. The apparent activation energies for methane and ethylene both decreased first from $35.89 \mathrm{~kJ} / \mathrm{mol}$ and $25.24 \mathrm{~kJ} / \mathrm{mol}$ at $20 \%$ to $15.22 \mathrm{~kJ} / \mathrm{mol}$ at $60 \%$ and $10.04 \mathrm{~kJ} / \mathrm{mol}$ at $50 \%$, and then increased to $27.03 \mathrm{~kJ} / \mathrm{mol}$ and $18.29 \mathrm{~kJ} / \mathrm{mol}$ at $80 \%$, respectively. For the gas component of propane, the apparent activation energy increased gradually from $10.64 \mathrm{~kJ} / \mathrm{mol}$ at $20 \%$ to $28.31 \mathrm{~kJ} / \mathrm{mol}$ at $80 \%$. The different variation trends of apparent activation energy for major gas components indicate that the formation of various gas products during the pyrolysis of toluene may proceed with different reaction mechanisms in the present study, which is further investigated.

\subsubsection{Reaction mechanisms}

Thermal decomposition of tar is a complex series of chain reactions such as parallel, multiple and consecutive reactions occurred during the stages of initiation, propagation and termination $[28,29,31]$. This study applied universal integral method $[13,38]$ to determine the most probable reaction mechanisms for toluene pyrolysis in MFBR. Eq. (1) can be further converted into Eq. (7):

$d x / f(x)=k(T) \times d t$

Taking the integration of the both sides of Eq. (7), and it can be further integrated into:

$G(x)=\int_{0}^{x} \frac{d x}{f(x)}=k(T) \times t$

where $G(x)$ is the integral reaction model. Based on Eq. (8), the points of $G(x)$ versus $t$ at different reaction temperatures can be fitted to a straight line, and the slope equal to $k(T)$. Nineteen kinds of reaction models were applied in the present study (Table S1). Five probable reaction models were selected first according to the quality of fitting correlation coefficient $\left(R^{2}\right)$ and standard deviation $(S D)$, which were illustrated in Fig. S1.

Then taking the logarithm of both sides of Eq. (3) can lead to the expression:

$\ln k(T)=-E_{a} / R T+\ln A$

According to Eq. (9), the plots between $\ln k(T)$ versus $1 / T$ generate a straight line with the slope equal to $-E_{a} / R$, which can determine the apparent activation energy once again. Tables S2-S5 illustrated the kinetic parameters for major gas components. Afterward, the most probable reaction model (Table 3) can be determined based on the closeness of the value of apparent activation energies obtained from the universal integral method and Friedman-Reich-Levi approach. Table 3 verified the speculation that the generation of individual gas composition proceeded with different reaction mechanisms. To be specific, three-dimensional diffusion was the most probable reaction mechanisms for hydrogen, while the evolution profiles of methane could be described

Table 3

Most probable reaction mechanisms for individual gas components.

\begin{tabular}{|c|c|c|c|c|}
\hline Gas & $E_{a}-\mathrm{FRL}(\mathrm{kJ} / \mathrm{mol})$ & $E_{a}-\mathrm{UI}(\mathrm{kJ} / \mathrm{mol})$ & Reaction mechanism & $G(x)$ \\
\hline $\mathrm{H}_{2}$ & 69.55 & 66.57 & Three-dimensional diffusion (Jander) & {$[1-(1-x) 1 / 3]^{2}$} \\
\hline $\mathrm{CH}_{4}$ & 23.27 & 23.41 & Nucleation and growth $(n=1 / 2)$ & {$[-\ln (1-x)]^{1 / 2}$} \\
\hline $\mathrm{C}_{2} \mathrm{H}_{4}$ & 17.59 & 19.98 & Chemical reaction $(n=0)$ & $x$ \\
\hline $\mathrm{C}_{3} \mathrm{H}_{8}$ & 16.34 & 17.05 & Chemical reaction $(n=1)$ & $-\ln (1-x)$ \\
\hline
\end{tabular}

Note: FRL: Friedman-Reich-Levi method; UI: Universal Integral method. 

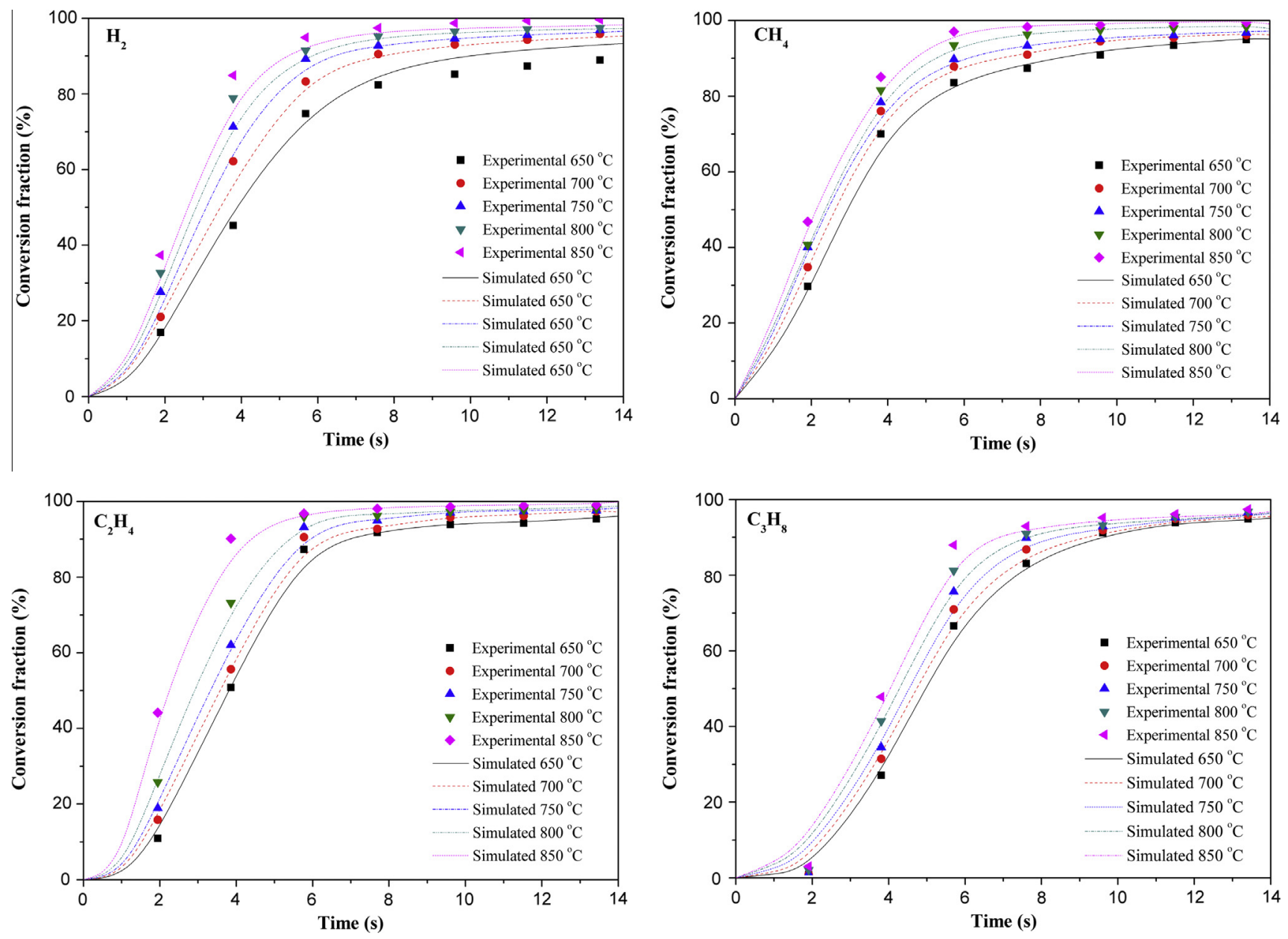

Fig. 3. Comparison of kinetic modeling (smooth curves) and experimental data (discrete points) for evolution profiles of gaseous products.

by the reaction mechanism of nucleation and growth. Chemical reaction was the most probable reaction mechanisms for ethylene and propane with different reaction orders.

Based on the developed reaction models and kinetic parameters, the numerical solutions to differential equations for evolution of the four gaseous products were simulated and then compared with the experimental results. Fig. 3 illustrated the time course of the evolution of four gaseous products at different temperatures. The good agreement between the simulation and experimental results suggests that the present model can be applied to evaluate the thermal cracking behavior of tar in the micro fluidized bed reactor, although there is some discrepancy between the experimental and estimated values at some points. However, it should be noted that there are some differences between the laboratory scale reactor used in the present study and pilot scale reactor. For example, microscale reactor can provide very high heat and mass transfer rates that are rarely achieved in an industrial reactor. Secondary cracking reactions are inevitable in an industrial reactor, which are barely observed in the microscale reactor. A detailed study of thermal cracking behaviors of tar in pilot scale may help us get a more comprehensive knowledge of tar reduction during biomass gasification, which is recommended for future study.

\section{Conclusions}

The thermal decomposition behavior of toluene as the model compound of light tar has been studied using a micro fluidized bed reactor. Experimental results indicated that toluene could be effectively decomposed into lighter gases by thermal cracking approach and reaction temperature was a key factor affecting the generation of major gas components. The time taken for reaction equilibrium of gaseous products in the present study was much shorter than other conventional thermal treatments due to higher heat and mass transfer rates in micro fluidized bed reactor. An increase in temperature promotes the decomposition reaction of toluene into main gaseous reaction products, including hydrogen, methane, ethylene and propane. The apparent activation energies for hydrogen, methane, ethylene and propane were $69.55 \mathrm{~kJ} / \mathrm{mol}$, $23.27 \mathrm{~kJ} / \mathrm{mol}, 17.59 \mathrm{~kJ} / \mathrm{mol}$ and $16.34 \mathrm{~kJ} / \mathrm{mol}$, respectively. Based on a comparison of kinetic models and experimental data, the proposed models were verified to be capable of predicting the thermal decomposition behavior of toluene.

\section{Acknowledgement}

The authors are grateful for financial support from National Key Foundation for Exploring Scientific Instrument (2011YQ120039).

\section{Appendix A. Supplementary material}

Supplementary data associated with this article can be found, in the online version, at http://dx.doi.org/10.1016/j.enconman.2015. 09.038 . 


\section{References}

[1] Hlina M, Hrabovsky M, Kavka T, Konrad M. Production of high quality syngas from argon/water plasma gasification of biomass and waste. Waste Manage 2014;34:63-6.

[2] Delgado J, Aznar MP, Corella J. Biomass gasification with steam in fluidized bed: effectiveness of $\mathrm{CaO}, \mathrm{MaO}$, and $\mathrm{CaO}-\mathrm{MgO}$ for hot raw gas cleaning. Ind Eng Chem Res 1997;36:1535-43.

[3] Branea C, Di Blsai C, Russo C. Devolatilization in the temperature range 300$600 \mathrm{~K}$ of liquids derived from wood pyrolysis and gasification. Fuel 2005;84:37-45.

[4] Jayaraman K, Gökalp I. Pyrolysis, combustion and gasification characteristics of miscanthus and sewage sludge. Energy Convers Manage 2015;89:83-91.

[5] Materazzi M, Lettieri P, Mazzei L, Taylor R, Chapman C. Reforming of tars and organic sulphur compounds in a plasma-assisted process for waste gasification. Fuel Process Technol 2015;137:259-68.

[6] Gai C, Dong Y. Experimental study on non-woody biomass gasification in a downdraft gasifier. Int J Hydrogen Energy 2012;37:4935-44.

[7] Han J, Kim H. The reduction and control technology of tar during biomass gasification/pyrolysis: an overview. Renew Sust Energy Rev 2008:12:397-416.

[8] Laksmono N, Paraschiv M, Loubar K, Tazerout M. Biodiesel production from biomass gasification tar via thermal/catalytic cracking. Fuel Process Technol 2013;106:776-83.

[9] Tao J, Lu Q, Dong C, Du X, Dahlquist E. Effects of electric current upon catalytic steam reforming of biomass gasification tar model compounds to syngas. Energy Convers Manage 2015;100:56-63.

[10] Patra TK, Sheth PN. Biomass gasification models for downdraft gasifier: a stateof-the-art review. Renew Sust Energy Rev 2015;50:383-93.

[11] Font Palma C. Modeling of tar formation and evolution for biomass gasification: a review. Appl Energy 2013;111:129-41.

[12] Ko KH, Rawal A, Sahajwalla V. Analysis of thermal degradation kinetics and carbon structure changes of co-pyrolysis between macadamia nut shell and PET using thermogravimetric analysis and $13 \mathrm{C}$ solid state nuclear magnetic resonance. Energy Convers Manage 2014;86:154-64.

[13] Gai C, Zhang Y, Chen W, Zhang P, Dong Y. Thermogravimetric and kinetic analysis of thermal decomposition characteristics of low-lipid microalgae. Bioresour Technol 2013;150:139-48.

[14] Gai C, Dong Y, Zhang T. The kinetic analysis of the pyrolysis of agricultural residue under non-isothermal conditions. Bioresour Technol 2013;127:298-305.

[15] Yu J, Zeng X, Zhang JW, Zhong M, Zhang GY, Wang Y, et al. Isothermal differential characteristics of gas-solid reaction in micro-fluidized bed reactor. Fuel 2013;103:29-36.

[16] Yu J, Yao CB, Zeng X, Geng S, Dong L, Wang Y, et al. Biomass pyrolysis in a micro-fluidized bed reactor: characterization and kinetics. Chem Eng 2011;168:839-47.

[17] Mao Y, Dong L, Dong Y, Liu W, Chang J, Yang S, et al. Fast co-pyrolysis of biomass and lignite in a micro fluidized bed reactor analyzer. Bioresour Technol 2015;181:155-62.

[18] Guo F, Dong Y, Lv Z, Fan P, Yang S, Dong L. Pyrolysis kinetics of biomass (herb residue) under isothermal condition in a micro fluidized bed. Energy Convers Manage 2015;93:367-76.

[19] Abdoulmoumine N, Adhikari S, Kulkarni A, Chattanathan S. A review on biomass gasification syngas cleanup. Appl Energy 2015;155:294-307.
[20] Świerczyński D, Libs S, Courson C, Kiennemann A. Steam reforming of tar from a biomass gasification process over Ni/olivine catalyst using toluene as a model compound. Appl Catal 2007;74:211-22.

[21] Sun Q, Yu S, Wang F, Wang J. Decomposition and gasification of pyrolysis volatiles from pine wood through a bed of hot char. Fuel 2011;90:1041-8.

[22] Gil J, Corella J, Aznar MP, Caballero MA. Biomass gasification in atmospheric and bubbling fluidized bed: effect of the type of gasifying agent on the product distribution. Biomass Bioenergy 1999;17:389-403.

[23] Brage C, Yu Q, Chen G, Sjöström K. Tar evolution profiles obtained from gasification of biomass and coal. Biomass Bioenergy 2000;18:87-91.

[24] Coll R, Salvado J, Farriol X, Montane D. Steam reforming model compounds of biomass gasification tars: conversion at different operating conditions and tendency towards coke formation. Fuel Process Technol 2001;74:19-31.

[25] Anis S, Zainal ZA, Bakar MZA. Thermocatalytic treatment of biomass tar model compounds via radio frequency. Bioresour Technol 2013;136:117-25.

[26] Taralas G, Kontominas MG, Kakatsios X. Modeling the thermal destruction of toluene $\left(\mathrm{C}_{7} \mathrm{H}_{8}\right)$ as tar-related species for fuel gas cleanup. Energy Fuel 2003; 17:329-37.

[27] Mani S, Kastner JR, Juneja A. Catalytic decomposition of toluene using a biomass derived catalyst. Fuel Process Technol 2013;114:118-25.

[28] Anis S, Zainal ZA. Study on kinetic model of microwave thermocatalytic treatment of biomass tar model compound. Bioresour Technol 2014;151:183-90.

[29] Jess A. Mechanisms and kinetics of thermal reactions of aromatic hydrocarbons from pyrolysis of solid fuels. Fuel 1996;75:1441-8.

[30] Fagbemi L, Khezami L, Capart R. Pyrolysis products from different biomasses: application to the thermal cracking of tar. Appl Energy 2001;69:293-306.

[31] Dufour A, Girods P, Masson E, Rogaume Y, Zoulalian A. Synthesis gas production by biomass pyrolysis: effect of reactor temperature on product distribution. Int J Hydrogen Energy 2009;34:1726-34.

[32] Evans RJ, Milne TA. Chemistry of tar formation and maturation in the thermochemical conversion of biomass. In: Bridgwater AV, Boocock DGB, editors. Developments in thermochemical biomass conversion, vol. 2. London: Blackie Academic \& Professional; 1997. p. 803-16.

[33] Swierczynski D, Courson C, Kiennemann A. Study of steam reforming of toluene used as model compound of tar produced by biomass gasification. Chem Eng Process 2008;47:508-13.

[34] Thurner F, Mann U. Kinetic investigation of wood pyrolysis. Ind Eng Chem Proc Des Dev 1981;20:482-8.

[35] Taralas G. Modelling the characteristics of the endothermic reaction potential of tar for flue gas cleanup in advanced thermochemical conversion processes. In: Bridgwater AV, editor. Progress in thermochemical biomass conversion. London: Blackie Academic \& Professional; 2001. p. 176-87.

[36] Slopiecka K, Bartocci P, Fantozzi F. Thermogravimetric analysis and kinetic study of polar wood pyrolysis. Appl Energy 2012;97:491-7.

[37] Friedman HL. Kinetics of thermal degradation of char-forming plastics from thermogravimetry. J Polym Sci Part C: Polym Symp 1964;6:183-95.

[38] White JE, Catallo W James, Legendre BL. Biomass pyrolysis kinetics: a comparative critical review with relevant agricultural residue case studies. J Anal Appl Pyrolysis 2011;91:1-33.

[39] Gai C, Liu Z, Han G, Peng N, Fan A. Combustion behavior and kinetics of lowlipid microalgae via thermogravimetric analysis. Bioresour Technol 2015;181:148-54. 